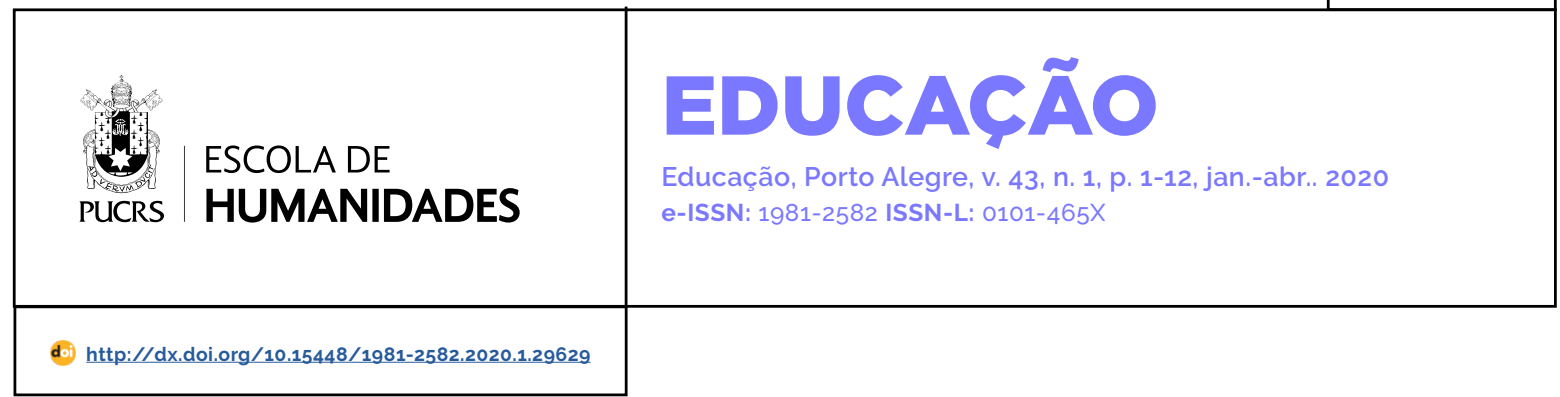

OUTROS TEMAS

\title{
O cultivo da singularidade como desafio para a formação humana
}

The cultivation of singularity as challenge for human formation

El cultivo de la singularidad como un desafio para la formación humana

\section{Diogo Bogéa ${ }^{1}$ \\ orcid.org/0000-0001-5862-819X \\ diogobogeaa@hotmail.com}

Recebido em: 11 jan. 2018. Aprovado em: 30 set. 2019 Publicado em: 25 mai. 2020.
Resumo: Todo processo de formação humana está ancorado em pressupostos metafísicos que envolvem uma certa concepção de "humano" e de "subjetividade" as quais, em geral, inquestionadas, perpassam as diretrizes, parâmetros, currículos, métodos e "correntes" pedagógicas. Nosso objetivo neste artigo será colocar em questão algumas concepções cristalizadas de "humano", "subjetividade" e "identidade", a fim de recolocar o processo de formação humana como problema e como desafio - e um desafio que não mais se resuma à aplicação de um método pré-definido cuja finalidade seja a realização de um ideal de humanidade e subjetividade previamente estabelecido. Para isso, recorreremos aos conceitos de "cultura" e "singularidade" na obra de Nietzsche, bem como à concepção de "subjetividade" que implicam.

Palavras-chave: Formação humana. Cultura. Singularidade.

Abstract: Every human formation process is based on metaphysical assumptions that involve a conception of "human" and "subjectivity" which, in general, unquestioned, pass through the guidelines, parameters, curriculums, methods and pedagogical "currents". Our aim in this paper is to question some crystallized conceptions of "humanity", "subjectivity" and "identity", in order to rethink the human formation process as something problematic and defiant - a challenge that no longer comes down to the application of a pre-established method which goal is the achievement of some ideal of humanity and subjectivity. For this, we will use the concepts of "culture" and "singularity" as they appear in Nietzsche's works, trying to explore the concept of subjectivity they imply.

Keywords: Human formation. Culture. Singularity.

Resumen: Todo proceso de formación humana está anclado en supuestos metafísicos que involucran una cierta concepción de "humano" y de "subjetividad" que, en general, incuestionables, pasan por las directrices, parámetros, curriculos, métodos y "corrientes" pedagógicas. Nuestro objetivo en este artículo será poner en cuestión algunas concepciones cristalizadas de "humano", "subjetividad" e "identidad", a fin de recolocar el proceso de formación humana como problema y como desafío - y un desafío que ya no se resuelve a la aplicación de un método predefinido cuya finalidad sea la realización de un ideal de humanidad y subjetividad previamente establecido. Para ello, recurriremos a los conceptos de "cultura" y "singularidad" en la obra de Nietzsche, así como a la concepción de "subjetividad" que implican.

Palabras clave: Formación Humana; cultura; singularidad 


\section{Introdução}

Se podemos afirmar com alguma segurança que a formação humana é sempre um desafio, a formação de professores é um desafio elevado à enésima potência, pois trata-se da formação daqueles cuja árdua missão será dedicar-se, eles próprios, à formação das novas gerações. Todo processo de formação humana está ancorado em pressupostos metafísicos que envolvem uma certa concepção de "humano" e de "subjetividade" as quais, em geral, inquestionadas, perpassam as diretrizes, parâmetros, currículos, métodos e "correntes" pedagógicas. Nosso objetivo neste artigo será colocar em questão algumas concepções cristalizadas de "humano", "subjetividade" e "identidade", a fim de recolocar o processo de formação humana como problema e como desafio - e um desafio que não mais se resuma à aplicação de um método pré-definido cuja finalidade seja a realização de um ideal de humanidade e subjetividade previamente estabelecido. Para isso, recorreremos aos conceitos de "cultura" e "singularidade" na obra de Nietzsche, bem como à concepção de "subjetividade" que implicam.

\section{Heranças da metafísica tradicional: sujeito, razão, cognitivismo}

A metafisica tradicional aposta historicamente no primado da razão, a qual é concebida como estando em condições de estabelecer fundamentos seguros e estáveis capazes de dar conta da totalidade da experiência humana de mundo. Com isso, tende-se a reduzir a complexidade humana à dimensão do "espírito", "alma", "entendimento", "intelecto" ou "consciência", enquanto moradas da racionalidade. Consequentemente, há um privilégio do conhecimento abstrato, teórico ou contemplativo como aquilo que, sendo o que há de mais próprio para o ser humano, cabe a ele, acima de tudo, desenvolver e realizar.

Pesquisas recentes em Filosofia da Educação vêm investigando as consequências dessa concepção reducionista do ser humano para o campo da educação, especialmente no que concerne à "sobrevalorização da dimensão cognitiva" (do Valle, 2003, p. 187), a qual determina o sentido da educação como um "só falar à razão" que tem a única finalidade de "instruir" (do Valle, 2003, p. 191).

"O grande precursor da hierarquização que estabelece a primazia do conhecimento sobre todas as demais atividades humanas é, sem dúvida, Platão", cujo projeto ético-político é condicionado pela "valorização do conhecimento teórico em detrimento do conhecimento prático". Essa valorização está assentada, ela própria, "sobre a ideia de que não somente é possivel um saber certo e infalivel sobre a educação (e sobre a política), mas que esse saber é o único que deve guiar sua realização" (do Valle, 2003, p. 187). A identificação platônica do "sabedor" ao "virtuoso" inaugura um novo modelo de areté, de virtude, calcado no conhecimento contemplativo abstrato das ideias eternas,

Podemos situar nesse gesto platônico um dos marcos iniciais da noção segundo a qual é sempre necessário um saber prévio, sólido e seguro, supostamente capaz de se dar como fundamento e garantia de qualquer prática educacional, ética ou política - noção que influenciará intensamente todo o posterior desenvolvimento do pensamento educacional: "Platão afirma a necessidade de uma investigação meticulosa e previamente determinada acerca das finalidades como condição e critério de validade para qualquer educação" (do Valle 2003, p. 187)

O pensamento moderno, centrado na presença a si do sujeito racional e consciente, tende a reduzir a experiência existencial humana à dimensão da racionalidade e da consciência, bem como a reduzir a experiência humana de mundo ao conhecimento, à cognição. Após assegurar-se de sua presença plenamente constituida a partir de uma relação intelectual interna consigo próprio, o sujeito moderno está apto a pôr o mundo diante de si enquanto objeto com o qual estabelece uma relação cognitiva representacional. A epistemologia salta ao primeiro plano da Filosofia e a questão mais relevante a partir de então é o estabelecimento do método capaz de assegurar a maior correção 
da representação cognitiva do mundo.

Segundo Danilo Marcondes, as duas "noções fundamentais" que caracterizam o pensamento moderno são "a ideia de progresso", que faz com que o novo seja considerado melhor ou mais avançado do que o antigo, trazendo consigo, portanto, ideais de "mudança, ruptura, progresso", "inovação" e "revolução", bem como a "valorização do indivíduo" ou da "subjetividade, como lugar da certeza e da verdade, e origem dos valores, em oposição à tradição, i. e., ao saber adquirido, às instituições, à autoridade externa" (Marcondes, 2007, p. 142). No entanto, não compreenderemos em que sentido se pode falar em "progresso" e "valorização da subjetividade" no contexto moderno se não estivermos suficientemente cientes da base de sustentação dessas noções, isto é, a razão. Está pré-estabelecido, como solo no qual podem ocorrer um progresso e uma valorização da subjetividade, uma determinada concepção de humano, a saber: o humano como ser racional e consciente, ou seja, o humano enquanto essencialmente determinado pela razão. O próprio Danilo Marcondes, no capítulo dedicado a Descartes, deixa transparecer essa condição:

A ideia de modernidade, como vimos anteriormente, está assim estreitamente relacionada à ruptura com a tradição, ao novo, à oposição à autoridade da fé pela razão humana e à valorização do indivíduo livre e autônomo, em oposição às instituições. [...] A crença no poder crítico da razão humana individual, a metáfora da luz e da clareza que se opõem à escuridão e ao obscurantismo, e a ideia de busca de progresso que orienta a própria tarefa da filosofia são alguns dos traços fundamentais da modernidade (Marcondes, 2007, p. 165).

Não é à toa que um dos marcos iniciais do pensamento moderno é o cogito de Descartes, que garante a caracterização essencial do ser humano como sujeito racional consciente - e autoconsciente:

Eu sou, eu existo: isto é certo; mas por quanto tempo? Durante todo o tempo em que eu penso; pois talvez poderia acontecer que, se eu parasse de pensar, ao mesmo tempo pararia de ser ou de existir. Nada admito agora que não seja obrigatoriamente verdadeiro: nada sou, então, a não ser uma coisa que pensa, ou seja, um espírito, um entendimento ou uma razão. (Descartes, 2000, p. 16, grifo do autor).

A moderna metafísica da subjetividade acaba por instaurar de uma vez a redução do ser humano ao domínio cognitivo:

Caracteristica da modernidade, a redução cognitivista [...] é o resultado do longo processo de substituição das "filosofias do espírito" tradicionais, de caráter marcadamente moralista, pelo "mentalismo" - que assimila o espírito a um conjunto de processos interiores capazes de definir um sujeito, ou um cogito, e que produzem as significações que ele fornecerá para as coisas exteriores. A rigor, o mentalismo começa com Descartes, para quem a busca das determinações da vida interior configurava a investigação sobre a origem e organização das ideias, ou sobre as representações subjetivas. Mas deve-se atribuir à progenitura mais direta de Locke a tendência moderna a privilegiar o estudo do "entendimento humano". isso é, a intenção de identificar as leis de funcionamento dos "estados mentais". (do Valle, 2014, p. 502).

É na experiência íntima de sua interioridade, na introspecção meditativa, que o sujeito faz a experiência de sua própria presença. A partir dessa autocertificação de si, o sujeito pode se dar como garantia e fundamento para o conhecimento seguro:

Para o cognitivismo moderno, é como
pura interioridade que a consciência
pode se fazer presença direta e trans-
parente do espirito a si mesmo, e é
nessa condição que ela se apresenta
como fundamento para o conhecimento
seguro. Logo, o fenômeno da cons-
ciência é garantido pela autonomia
dos processos mentais, que a filosofia
do espírito afirma, ao destacá-los do
mundo exterior. (do Valle, 2014, p. 502).

Se o autoconhecimento se dá na imediatidade da presença a si através de uma introspecção mental, o ser humano, o "ser" do humano, enquanto efetivamente presente e apreensivel por essa experiência introspectiva, é reduzido à dimensão mental-cognitiva:

Nisto consiste o cognitivismo: na crença de que, situado no "interior" do indi- 
víduo, o espírito nada mais é do que presença que se traduz inteira e exaustivamente como conhecimento de si conhecimento direto e intuitivo de suas representações ou operações mentais. O cognitivismo realiza, assim, uma dupla redução, drástica tanto em sua amplitude quanto em suas consequências, pois: (1) para que toda experiência de si, toda experiência da própria existência possa ser definida como cognição, é preciso, primeiramente, que (2) se converta o conjunto das dimensões humanas ao elemento mental. [...]. Na cena interior, em que existência é cognição, o espírito descobre sua "autonomia" em relação aos fenômenos, às coisas dadas; e essa "absolutização" do espírito - do cogito, da mente, da subjetividade transcendental - torna-se a própria marca do tipo de conhecimento que a modernidade instala no panteão de suas conquistas mais duradouras. (do Valle, 2014, p. 504).

É somente a partir da presença-a-si do sujeito racional que se faz possivel a experiência do "mundo externo" - enquanto objeto posto diante da consciência subjetiva. A "consciência-cogniçãorazão é condição e é medium da presença aos fenômenos - entre os quais há que se incluir aqueles que tocam à existência empírica do sujeito" (do Valle, 2014, p. 504). Essa concepção de ser humano que reduz sua essência e sua presença à dimensão cognitiva encontra "muitas dificuldades para lidar com tudo que não se deixa reduzir à cognição, ao conhecimento imediato e transparente" (do Valle, 2014, p. 504) que a introspecção mental subjetiva supostamente proporciona.

Mesmo na corrente empirista, que se contrapõe a Descartes quanto à origem das ideias e do conhecimento, há ainda um privilégio da dimensão cognitiva, pois a valorização da experiência sensivel somente se dá na medida em que o corpo e os sentidos são compreendidos como receptores e coletores de dados brutos da experiência que serão impressos na tabula rasa mental e, por fim, devidamente processados pela razão. Ou seja, mesmo na tradição moderna empirista o homem permanece sendo essencialmente "sujeito do conhecimento" e reduzido ao domínio cognitivo. No caso de Locke:

Sua refutação da doutrina das ideias inatas parte do questionamento de que as ideias possam estar impressas no homem, independentemente de sua percepção. Esse questionamento o levará à definição de que o pensamento está inteiramente identificado à consciência do pensamento, ou seja: o pensar consiste em ter consciência de que se pensa. Seu passo seguinte será a fundação empírica do conhecimento, ao afirmar que nada se encontra no entendimento humano que não tenha antes estado nos sentidos. No entanto, a consciência é o núcleo constitutivo de sua filosofia, que, por isso mesmo, pode ser chamada de racionalista. Para Locke, a mente é um conjunto de operações que fazem existir as ideias. A cognição encontra-se no centro da definição da identidade individual em Locke, que acaba por menosprezar a questão dos afetos, dos desejos e da imaginação, por não considerá-los como aspectos adequados a uma compreensão segura pelo conhecimento humano. O mesmo se dá em relação à própria corporeidade, da qual [...] interessa apenas as sensações, na medida em que provocam alterações mentais claras e distintas, convertendo-se em material para o pensamento. (Sanchez, 2008, p. 7).

A herança dessa concepção metafísica que reduz o humano à dimensão cognitiva se faz presente na maioria das reflexões contemporâneas sobre educação, determinando a ênfase na cognição e na "aprendizagem" - a apreensão intelectual de conteúdos - como focos centrais e finalidades supremas do processo de formação humana.

\section{Cultura e cultivo}

Construir uma maneira diferente de pensar a formação humana exige, portanto, uma crítica radical dos pressupostos metafísicos que fundamentam essa concepção tradicional de subjetividade. Para tanto recorreremos à obra de Friedrich Nietzsche, pensador que nos ajudará a situar nossas reflexões sobre o "sujeito" e, consequentemente, sobre a "formação humana", para além do registro propriamente moderno.

Não sem razão, Danilo Marcondes apresenta Nietzsche da seguinte maneira em seu Iniciação à História da Filosofia: "o pensador cuja critica à tradição filosófica, clássica e moderna foi mais marcante" (Marcondes, 2007, p. 248). Critica marcante que 
abala os pilares de sustentação da modernidade: o sujeito como núcleo racional e consciente subsistente em si e por si mesmo; a compreensão progressiva, linear e teleológica de tempo e de história; e os ideais morais que condicionam a vida humana à busca de uma felicidade eterna no "além" ou à busca de uma pequena felicidade burguesa que consiste na dedicação a um trabalho formal visando a acumulação de bens e capital, pontilhada por intervalos de descanso confortável e alguma diversão.

Não compreenderemos a crítica nietzschiana à metafísica tradicional e à modernidade se não compreendermos, em primeiro lugar, o que está em jogo para ele nessa atitude crítica. Não se trata de uma simples rebeldia ou revolta contra a tradição, nem de um mero prazer lúdico na iconoclastia desenfreada. 0 problema fundamental a partir do qual Nietzsche se lança destrutivamente em direção aos ídolos metafísicos é o problema da cultura, ou, nos termos da Filosofia da Educação, o problema da formação humana. Não por acaso, Rosa Dias inicia o seu texto "Nietzsche: Educador da Humanidade" com a afirmação: "a educação ocupa, na filosofia de Nietzsche, um lugar central". A máxima de Pindaro torna-te quem tu és "dá a direção ao seu projeto educacional" (Dias, 2012, p. 2). Katia Muricy, por seu turno, afirma que:

A reflexão sobre a cultura constituiu o eixo central do pensamento de Nietzsche, desde os seus textos juvenis, voltados para a cultura grega e para as considerações estéticas - como é, exemplarmente o caso de O nascimento da tragédia - mas também nos escritos posteriores. (Muricy, 2000, p. 55).

Mas o que significa aqui cultura? Precisamos nos ocupar, em primeiro lugar, em desvendar o profundo sentido que a palavra cultura guarda no projeto de pensamento nietzschiano. Trata-se de um sentido muito peculiar, que remete tanto à raiz etimológica latina cultura quanto às noções de Kultur e especialmente de Bildung, ambas forjadas, lapidadas e desdobradas na fertilissima atmosfera espiritual da Alemanha do século XVIII. Sentido muito peculiar que, se tomarmos em conta o longo desenvolvimento histórico da humanidade, encontra-se relativamente próximo de nós, já que menos de trezentos anos nos separam, mas que em termos de compreensão e significado parece estar infinitamente distante do uso que habitualmente fazemos do termo "cultura".

O livro O que é cultura, um dos números de uma famosa coleção da editora Brasiliense, nos fornece indicações precisas do significado usual que atualmente o termo "cultura" assume:

Cultura está muito associada a estudo, educação, formação escolar. Por vezes se fala de cultura para se referir unicamente às manifestações artísticas, como o teatro, a música, a pintura, a escultura. Outras vezes, ao se falar na cultura da nossa época ela é quase que identificada com os meios de comunicação de massa, tais como o rádio, o cinema, a televisão. Ou então cultura diz respeito às festas e cerimônias tradicionais, às lendas e crenças de um povo, ou a seu modo de se vestir, à sua comida, a seu idioma. A lista pode ser ampliada. (Santos, 2006, p. 19).

Embora possa também ser utilizada de uma "maneira mais genérica", abarcando "tudo o que caracteriza uma população humana" (Santos, 2006, p. 19).

Todas essas definições possiveis, por mais diferentes que sejam, são atravessadas por uma constante, um modo de ser invariável que faz com que todas elas se prestem a um mesmo tipo de apreensão: em todos esses casos, cultura é compreendida como "algo" dado e, portanto, apreensivel em si e, enquanto tal, passivel de uma definição exata, de uma descrição e de uma apresentação. Manifestações artísticas, meios de comunicação de massa, tradições e crenças, vestimenta, comida e idioma de um povo são aqui compreendidos como um conjunto de fatos objetivos capazes de definir satisfatoriamente o que seja "cultura". Mesmo no primeiro exemplo do autor, que parece fugir a essa dinâmica de apresentação objetificante, a mesma lógica permanece vigente. Por "estudo, formação e educação escolar", compreende-se hoje a mera aquisição e acúmulo de conteúdos considerados relevantes - sejam eles de ordem científica, moral 
ou artística -, o que fica evidente em um dos usos correntes que se faz da palavra "cultura" em referência a esse processo de "educação formal", isto é, quando se diz que alguém "tem muita cultura", como sinônimo de que por meio do estudo adquiriu uma grande quantidade de conteúdos intelectuais relevantes.

Na Alemanha de Nietzsche havia pelo menos duas maneiras de se dizer "cultura". A primeira, derivada do latim: Kultur. Em seu famoso O processo civilizador, Norbert Elias discorre longamente sobre a gênese e o desenvolvimento deste conceito entre os alemães. "O conceito alemão de Kultur alude basicamente a fatos intelectuais, artísticos e religiosos" e tende a "traçar uma nitida linha divisória entre fatos deste tipo, por um lado, e fatos políticos, econômicos e sociais, por outro" (Elias, 1994, p. 24). Kultur referese a "obras de arte, livros, sistemas religiosos ou filosóficos nos quais se expressa a individualidade de um povo" (Elias, 1994, p. 25).

O outro conceito alemão para "cultura" é Bildung, termo que "norteou a elaboração de todo um sistema axiomático e ideológico em torno da cultura" (Britto, 2010, p. 1). Bildung diz "formação cultural" e "expressa, sobretudo, o processo da cultura" (Suarez, 2005, p. 196, grifo do autor). Bildung, portanto, não se deixa apreender, à maneira das nossas definições contemporâneas para "cultura" como "algo" capturável, definível e apresentável em si, pois se dá como processo dinâmico, além de comportar em si uma vasta gama de significações entrelaçadas:

A palavra alemã Bildung significa, genericamente, "cultura" e pode ser considerado o duplo germânico da palavra Kultur, de origem latina. Porém, Bildung remete a vários outros registros, em virtude, antes de tudo, de seu riquíssimo campo semântico: Bild, imagem, Eindbildungskraft, imaginação, Ausbildung, desenvolvimento, Bildsamkeit, flexibilidade ou plasticidade, Vorbild, modelo, Nachbild, cópia, e Urbild, arquétipo. Utilizamos Bildung para falar no grau de "formação" de um individuo, um povo, uma língua, uma arte: é a partir do horizonte da arte que se determina, no mais das vezes, Bildung. Sobretudo, a palavra alemã tem uma forte conotação pedagógica e designa a formação como processo. (Berman como citado em Suarez, 2005, p. 193).
Inicialmente, Bildung foi apropriada e utilizada pela mística barroca e dos primeiros românticos, para os quais assume o aspecto de uma "forma interna" que revelava "a inescapabilidade de um processo de formação qualquer, sustentado por uma providência transcendente que havia produzido essa forma" (Britto, 2010, p. 3). Por outro lado, pelas Ciências Naturais, no conceito de Bildungstrieb, um "impulso de formação que explicaria a energia presente em todos os corpos" (Britto, 2010, p. 3. grifo do autor) e que marca a substituição de um paradigma biológico estático, baseado em estruturas e caracteres, por um paradigma dinâmico, baseado em forças e impulsos. No contexto da Aufklärung o conceito assume uma conotação política, uma vez que "no interior das teorias políticas da Aufklärung. o problema da educação individual e da cultura parecem ter se fundido sob a forma geral de uma educação para a cidadania" (Britto, 2010, p. 5).

Decisiva para a geração de Nietzsche é a abordagem de Humboldt, "a figura emblemática da pedagogia alemã desde o começo do século", o qual logrou reunir "pela primeira vez, o conjunto de problemas relacionados às condições teóricas e ao horizonte ideológico" no interior do qual os principais conceitos pedagógicos "deveriam ser discutidos" (Britto, 2010, p. 9, grifo do autor). Enquanto na atmosfera das luzes, a ideia de formação cultural está intrinsecamente associada - ou mesmo subordinada - às exigências políticas de formação do cidadão para a vida em sociedade, a partir de Humboldt, Bildung passa a ser compreendida como uma tarefa individual de autoformação no sentido de desenvolvimento maximal das "forças" e "potencialidades" individuais - processo esse que encontra a sua finalidade em si mesmo, já que é alçado à condição de finalidade suprema da humanidade. Humanidade - e não sociedade - que cada um eleva à excelência no próprio processo formador que realiza em si mesmo. A partir de Humboldt, portanto, o tom da discussão se torna o seguinte:

a destinação do homem reside exatamente na realização de sua Bildung 
enquanto processo de desenvolvimento pleno de suas forças ou potencialidades individuais, e a sociedade - menos cosmopolita e mais nacionalista que em Kant ou Fichte - funciona como meio desse processo. Não que a humanidade, para além das existências individuais, não seja mais fundamental: na verdade, ela é "a tarefa última da nossa existência [...]", mas aqui se dissocia, ao menos epistemologicamente, o elo entre humanidade e sociedade que ainda estava presente no tratamento da história em Kant. Desse modo, a humanidade não é a antitese do indivíduo, mas sua realização mesma, sua elevação, através da Bildung, a um patamar existencial mais elevado - pois "o conceito de humanidade" está "em nossa Pessoa". (Britto, 2010, p. 10).

Através desse percurso histórico de apropriações e transformações, Bildung torna-se um dos conceitos mais decisivos da modernidade alemã, um conceito aglutinador das discussões acerca da identidade alemã, dos projetos futuros da nação e reúne em torno de si as figuras proeminentes de diversos círculos - filósofos, artistas, políticos, professores, cientistas etc.

Das ciências naturais às assembleias políticas, das cátedras de filologia às associações estudantis, o tema da urgência de uma Bildung por vir, capaz de resgatar no povo alemão sua identidade e grandeza, condicionou o tom do discurso predominante em todos os circulos onde a ideia de cultura pudesse ter alguma relevância ao longo do século XIX. Preocupada em constituir para si a imagem unificada de sua nacionalidade nas décadas que se prepararam dificilmente para a unificação de 1871 , a sociedade alemã procurou enxergar no problema da formação cultural sua história, sua eficiência política e econômica, sua destinação, e fez dele a tábula rasa de todo e qualquer discurso que se pretendesse como alemão e, especialmente, moderno no sentido muito singular, mesmo paradoxal, em que se deu o processo de modernização na Alemanha. Poucos debates teóricos ocuparam com tanta amplitude o horizonte politico de uma sociedade e foram capazes de reunir, em uma mesma polêmica, ainda que com diferentes niveis de participação, imperadores, estrategistas militares, professores universitários, o público leitor de jornais, cientistas, músicos, economistas, filósofos e estudantes secundaristas. É no meio de nomes como Bismarck, Richard Wagner, Pestalozzi, Schopenhauer e Friedrich
David Strauss que a filosofia da cultura que Nietzsche havia desenvolvido em seus primeiros escritos encontra seu lugar. (Britto, 2010, p. 9).

A partir desses referenciais nos colocamos em condições de começar a compreender o profundo sentido que a palavra cultura guarda para Nietzsche, pondo-se mesmo como guia norteador de todo o seu esforço de pensamento. Para Nietzsche cultura não é acúmulo de conhecimento, nem um conjunto de fatos dados, sejam materiais ou imateriais, relativos à existência de um povo. Cultura é cultivo, o cultivo de si, o processo de formação cuidadosa de si na dedicação disciplinada a atividades artísticas, em um sentido que não se reduz às "belas artes", mas que diz respeito a um engajamento criador e libertador que produza afirmativamente diferenças e singularidades. Cultivando a si mesmo rumo à excelência, o indivíduo eleva consigo a própria humanidade à excelência. Cultura é cultivo das próprias potencialidades de modo a formar em si um todo complexo em que as multiplicidades, com suas tensões e conflitos, não se aniquilem. nem gerem uma dispersão irreconciliável, mas se articulem em uma composição capaz de gerar os mais exuberantes e singulares frutos.

\section{O desafio da singularidade}

O "primeiro princípio" da cultura, tal como enunciado por Nietzsche na obra Schopenhauer Educador, a "única tarefa" que a cultura propõe "a cada um de nós", seria "incentivar o nascimento do filósofo, do artista e do santo em nós e fora de nós" (Nietzsche, 2003, p. 180). Nietzsche afirma que se impõe a cada um que assuma para si esta tarefa, a "luta pela cultura, a hostilidade com relação às influências, aos hábitos, às leis, às instituições nas quais ele não reconheça seu objetivo: o engendramento do gênio" (Nietzsche, 2003, p. 184). "Santo", "gênio" e "herói", palavras utilizadas por Nietzsche para se referir aos "casos excepcionais" da humanidade, são por demais carregadas do espírito romântico que ainda embalava o seu tempo. Podemos pensar essa "excepcionalidade" a ser cultivada em cada um 
de nós como singularidade. Afinal, não precisamos recorrer a um ideal de "santidade", "genialidade" ou "heroísmo" para pensar a excepcionalidade, se levarmos em consideração que cada um de nós, como constituido por uma combinação única de circunstâncias, é já, porque absolutamente singular, excepcional. Mas essa singularidade e essa excepcionalidade, tendem a ser obliteradas e absorvidas, em cada época, por projetos identitários universalizantes e totalizantes. Portanto, ao mesmo tempo que a singularidade é já sempre uma realidade para cada um de nós, é também sempre necessariamente uma singularidade a ser construida e conquistada. A "única tarefa" que a cultura nos impõe seria, portanto, preparar em nós e em torno de nós, a emergência da singularidade.

Pensar a cultura como processo, como experiência do cultivo de si enquanto singularidade, envolve uma outra maneira de se relacionar consigo mesmo, com o conhecimento, com a época e com a história. Envolve, portanto, uma outra maneira de se conceber a subjetividade.

Assumir o desafio da cultura como cultivo de si é colocar-se em uma relação problemática e conflituosa com o próprio tempo. Enquanto as "influências" e "instituições" do seu tempo pressionam no sentido de uma homogeneização conformadora e conformista que dilui as singularidades em uma "comunidade" préfabricada, colocando a cultura a serviço de um Estado, de uma classe, de um partido, de uma ideologia, de uma religião, o desafio de tornar-se quem se é exige que se dê ouvidos ao apelo da sua singularidade irredutivel, a qual demanda um desenvolvimento pleno através da verdadeira cultura, do cultivo de si. Assim, o humano sempre necessariamente "histórico", depara-se com uma dimensão "supra-histórica" a ser conquistada, na medida em que rompe a cadeia evolutiva linear da sua época, afastando-se, ou mesmo opondo-se abertamente às tradições, exigências, influências e instituições próprias do seu tempo. A "força artística" que nos atravessa e nos constitui "tem como obstáculo a sua irrupção", a concepção de que seriamos "fruto de uma evolução de um estado de coisas e não, ao contrário, justamente a ruptura de uma continuidade". Para Nietzsche, a singularidade "não resulta do progresso previsivel de uma cultura, mas de uma ruptura incontornável na tradição". (Muricy, 2000, p. 64)

A cultura envolve, portanto, um tornar-se "intempestivo", "inatual", à medida que se age "contra o tempo", "sobre o tempo" e em favor "de um tempo por vir" (Nietzsche, 2008, p. 17).

O trabalho da cultura, conduzida pelo [...] intempestivo - é Bildung, isto é, um cultivo, uma formação. A cultura (Kultur) deve proporcionar o trabalho de cultivo [...]. Neste contexto, a educação se fará muito mais pelo exemplo único do que por uma pedagogia uniformizadora. Uma educação verdadeiramente culta visará ao cultivo de si, isto é, terá como objetivo promover o indivíduo como "caso único". A cultura filistéia, ao contrário, constitui-se pela negação da irredutibilidade do individuo, pois nela a opinião pública sobrepõe-se à opinião do individuo. (Muricy, 2000, p. 65).

Movido por um apelo de singularização e promoção da cultura, o cultivo de si põe o humano em guerra contra o seu tempo. Todos somos, enquanto seres historicamente situados, constituidos pelas múltiplas e diversas circunstâncias socioculturais do nosso tempo. Contra a concepção moderna de um sujeito previamente dado e plenamente constituido em si e por si mesmo, Nietzsche nos lembra que somos efeito das múltiplas e diversas circunstâncias de todas as ordens que nos atravessam e nos constituem: "você é feito! A cada momento!" (Nietzsche, 2005, p. 59, grifo do autor). Lutar contra a época presente envolve, portanto, o arriscado movimento de voltar-se criticamente contra si próprio. No entanto, essa luta e essa crítica são imprescindiveis, pois se dirigem às instituições, hábitos e maneiras de pensar estabelecidas que, tentando nos enquadrar em definições fechadas e pré-fabricadas, totalizantes, universalizantes e, com isso, homogeneizantes, sufocam nossa irredutivel singularidade.

Se de fato preferimos considerar todo grande homem como o verdadeiro filho do seu tempo e como aquele que sofre. em todo caso, com todas as mazelas 
deste tempo, da maneira mais intensa e com mais sensibilidade [...] o combate deste grande homem contra seu tempo só aparentemente é um combate absurdo e destruidor contra si mesmo. Mas isto é somente na aparência, pois, no seu tempo, ele combate o que o impede de ser grande, o que para ele só pode exatamente significar: ser livre e totalmente si mesmo. Segue-se que sua hostilidade é no fundo dirigida contra o que está nele próprio, certamente. mas não é verdadeiramente ele próprio, dirigida contra a mistura impura e confusa de elementos incompativeis para sempre inconciliáveis, contra a falsa união do atual com seu próprio caráter intempestivo; e no fim, revela-se que o pretenso filho do seu tempo é somente um bastardo (Nietzsche, 2003, p. 162, grifo do autor).

Afinal, cada um "sabe muito bem que não se vive no mundo senão uma vez, na condição de único, e que nenhum acaso, por mais estranho que seja, combinará pela segunda vez uma multiplicidade tão diversa nesse todo único que se é" (Nietzsche, 2003, p. 138). No entanto, "esconde isso como se tivesse um remorso na consciência - por quê? Por medo do próximo que exige esta convenção e nela se oculta" (Nietzsche, 2003, p. 138). Somente "os artistas", diz Nietzsche, "odeiam" o "desleixado deixar-correr, revestido de maneiras tomadas de empréstimo e de opiniões postiças". Eles sabem que "todo homem" é um "milagre único" e não estão dispostos a ignorar este fato em nome da "boa consciência" social. Quando "se recusa a fazer parte da massa", o artista precisa "renunciar à sua indulgência para consigo mesmo" e obedecer à sua consciência que the grita: "Sê tu mesmo! Tu não és isto que agora fazes, pensas e desejas'" (Nietzsche, 2003, p. 139). Vale ressaltar que a referência ao "artista" nesse caso não diz respeito apenas aos músicos, poetas, pintores etc., mas às potencialidades criadoras que nos atravessam e nos constituem, abrindo para cada um de nós a possibilidade de atuar criativamente, como verdadeiros artistas, em nossa autoformação.

O cultivo da própria singularidade é, por um lado, uma tarefa solitária, justamente porque, contra as instituições castradoras e homogeneizantes, na contracorrente da paz de espírito conformista da opinião pública, impõe que se desça "até as profundezas da existência" para the fazer uma série de "perguntas insólitas": "Por que é que vivo? Que lição devo aprender com a vida? Como me tornei o que sou e por que devo eu sofrer por ser assim?" (Nietzsche, 2003, p. 173). Perguntas que "nem a ciência, nem a política, nem a vitória econômica e militar, nem o Estado, nem a moral ou a religião, poderiam responder" (Muricy, 2000, p. 66). "Ninguém pode construir no teu lugar a ponte que te seria preciso tu mesmo transpor no fluxo da vida - ninguém, exceto tu" (Nietzsche, 2003, p. 140). Por outro lado, é uma tarefa que envolve uma genuína preocupação com o outro, já que não cessa de procurar preparar não apenas em si, mas também "ao redor de si", o surgimento da singularidade. O cultivo de si não cessa de voltar-se para o outro como inspiração e chamado a responder, também ele, ao desafio da cultura. Além do mais, a militância cultural contra todos aqueles aspectos e instituições da época que procuram fornecer definições e sentidos préfabricados e homogeneizantes para um suposto "nós", não cessa de preparar o caminho para o outro, para que se lance, ele também, rumo ao árduo processo de singularização.

É importante ressaltar que a "singularidade" desse "si mesmo" à qual Nietzsche se refere, muito difere da "individualidade" moderna de um sujeito ontológico, epistemológico e político constituido como algo dado em si e por si mesmo, presente-a-si enquanto razão e consciência autoapreensivel na experiência imediata de sua interioridade. Trata-se de um "si mesmo" e de uma "singularidade" em construção e sempre ainda por construir, nas experiências de articulação criativa das circunstâncias - múltiplas, outras, "exteriores" - que o constituem enquanto tal.

A busca desse eu é problemática: não
se trata de procurar por algo previa-
mente conhecido, de algo que existiria
antes dessa busca como, por exemplo,
uma "verdadeira natureza humana" ou
uma "essência humana" degradada.
Tampouco é a busca de um eu psicoló-
gico, de um desejo constituinte ou qual-
quer outra instância interior [...]. Assim,
a proposta de um radical "torna-te tu
mesmo" não pode ser confundida coma 
valorização psicológica de uma interioridade. Ao contrário, a busca desse eu é um problema de exterioridade (Muricy, 2000, p. 66, grifo do autor).

Não se trata, portanto, do reencontro de uma unidade essencial ou de uma identidade fundamental previamente dada. Trata-se, muito mais propriamente, da construção, ou melhor, do cultivo de um "si mesmo" para além da autoimagem ou da imagem social habituais que cotidianamente se compreende como um "eu". Cultivo de "si mesmo" para além de si mesmo, algo que justamente começa a tomar forma no processo de formação cultural que até aqui procuramos pensar: na preparação da singularidade em si e ao redor de si, o que envolve a luta determinada contra os elementos da própria época que massificam e puxam para baixo e a dedicação disciplinada à realização de uma obra e de um legado que, enquanto singular, eleva o seu criador, em primeiro lugar à condição de criador e, portanto, à condição de singularidade e excepcionalidade. "Pois tua essência verdadeira não está oculta no fundo de ti, mas colocada infinitamente acima de ti, ou pelo menos daquilo que tomas comumente como sendo teu eu" (Nietzsche, 2003, p. 141).

Trata-se de uma compreensão da subjetividade que desconstrói também as oposições metafísicas, muito caras à modernidade, entre "interior" e "exterior", "conteúdo" e "forma". Não se trata de "unificar" essas dimensões cindidas, mas de desfazer a ilusão metafísica vigente segundo a qual é possivel cultivar um "interior" preenchendo-o de inumeráveis "conteúdos", à maneira de "enciclopédias ambulantes" (Nietzsche, 2008, p. 52), sem que isso necessariamente esteja permanentemente articulado à exteriorização, isto é, à realização de uma obra. Quando isso ocorre, é como se, curiosamente, um solo se tivesse tornado infértil por excesso de fertilizantes.

A desgastada oposição entre forma e conteúdo, exterior e interior é aproveitada por Nietzsche como uma espécie de estratégia de discurso para revelar a limitação desse tipo de pensamento.
É o povo que, preso nas malhas da gramática/metafísica hipervaloriza o conteúdo e só consegue pensá-lo como algo oposto à forma. [...] Promover a unidade, para Nietzsche, não consiste em simplesmente juntar o que estava separado, harmonizar esses termos. Tampouco consiste em conciliá-los num terceiro termo, ao modo de uma sintese dialética, mas chegar ao entendimento de que o próprio "conteúdo" já é sempre "forma" (e vice-versa) e de que não é possivel tomá-los isoladamente, a supressão de um sendo já a eliminação de ambos. (Bieri, 2000, p. 129).

A modernidade confunde "instrução" com "cultura" (Nietzsche, 2008a, p. 18), julgando que um acúmulo de conteúdos intelectuais relevantes é sinônimo de "cultura", quando cultura corresponde ao processo de cultivo de si, a serviço do qual deve ser posta a busca do saber:

\begin{abstract}
O saber, absorvido imoderadamente e sem que a ele se seja impelido pela fome, mesmo absorvido por conta da necessidade, não age mais desde então como motivo transformador, impelindo para o exterior, mas fica escondido numa espécie de mundo interior, caótico, que, com uma singular altivez, o homem moderno chama a "intimidade" que the é peculiar. Às vezes chega até a dizer que se domina muito bem o assunto, mas que é somente a forma que faz falta. Mas para tudo o que é vivo, essa é uma oposição incoerente (Nietzsche, 2008, p. 51).
\end{abstract}

Para Nietzsche, cultura não é acúmulo de conhecimento, nem um conjunto de fatos dados, sejam materiais ou imateriais, relativos à existência de um povo. Cultura é cultivo, o cultivo de si, o processo de formação cuidadosa de si na dedicação disciplinada a atividades artísticas, em um sentido que não se reduz às "belas artes", mas que diz respeito a um engajamento criador e libertador que produza afirmativamente diferenças e singularidades. Cultivando a si mesmo rumo à excelência, o individuo eleva consigo a própria humanidade à excelência. Cultura é cultivo das próprias potencialidades - e das próprias circunstâncias que nos constituem - de modo a formar em si um todo complexo em que as multiplicidades, com suas tensões e conflitos, não se aniquilem, 
nem gerem uma dispersão irreconciliável, mas se articulem em uma composição capaz de gerar os mais exuberantes e singulares frutos.

A cultura "é um processo longo, uma tarefa de tipos intempestivos, à contracorrente da opinião pública" (Muricy, 2000, p. 64). No entanto, a "grande originalidade" dessa concepção de cultura é justamente o que os críticos poderiam considerar o seu "ponto mais fraco": o "'elitismo' de sua proposta" (Muricy, 2000, 65). Pois "é justamente essa concepção o que the permite valorizar uma ética individual de generosidade em oposição ao egoísmo da desenfreada 'caça à felicidade'" que move o espírito moderno.

\begin{abstract}
Se são individuos determinados Goethe, Schopenhauer, Wagner etc que Nietzsche toma como exemplares da verdadeira cultura, estes individuos consistem, no entanto, tipos. Erigindoos em uma tipologia, Nietzsche ultrapassa os limites de uma análise subjetiva da cultura. Quando [...] propõe como o verdadeiro trabalho da cultura proporcionar o aparecimento destes tipos, seu ponto de partida é a individualidade, com ênfase no "caso único", um eu irredutivel que é cada homem como meta da Bildung. (Muricy, 2000 , p. 66, grifo do autor).
\end{abstract}

Se hoje tendemos a desconfiar de uma proposta ética voltada para o "cultivo de si" ao invés de já imediatamente preocupada com os princípios que devem reger nossa relação com os outros, é devido aos milênios de domínio da moralidade cristã, que tem como base justamente um certo ideal de "altruismo" e de "abnegação" de si em favor dos "outros". É o que Foucault expõe com muita propriedade na seguinte passagem:

Ora, nós bem sabemos, existe uma certa tradição (ou talvez várias) que nos dissuade (a nós, agora, hoje) de conceder a todas estas formulações, a todos estes preceitos e regras, um valor positivo e, sobretudo, de deles fazer o fundamento de uma moral. Como soam aos nossos ouvidos, estas injunções a exaltar-se, a prestar culto a si mesmo, a voltar-se sobre si, a prestar serviço a si mesmo? Soam como uma espécie de desafio e de bravata, uma vontade de ruptura ética, uma espécie de dandismo moral, afirmação-desafio de um estádio estético e individual intransponivel' Ou então, soam aos nossos ouvidos como a expressão um pouco melancólica e triste de uma volta do individuo sobre si, incapaz de sustentar, perante seus olhos, entre suas mãos, por ele próprio, uma moral coletiva (a da cidade, por exemplo), e que, em face do deslocamento da moral coletiva, nada mais então teria senão 'ocupar-se consigo', Isto significa, se quisermos, que estas conotações, estas ressonâncias primeiras que, de imediato, todas estas fórmulas têm para nós, dissuadem-nos de pensar estes preceitos com valor positivo. (Foucault, 2006, p. 16-17).

Curiosamente, parecemos sempre prontos a desconfiar do aparente "egoísmo" de projetos éticos baseados no "cultivo de si", mas impressiona a nossa histórica inabilidade para levantar suspeitas em relação a projetos universalizantes e totalizantes que, sufocando mais ou menos violentamente as singularidades, se apresentam a cada vez como defensores de um "bem" e uma "verdade" supostamente válidos para "todos nós".

Fica aqui a pergunta: [...] "todos" ... quem? E quem é que diz ... "todos"? Quem unifica, consigna e arquiva as coisas em nome de todos, para todos ou a serviço de todos? Mesmo que esses "todos" sejam sempre alguns. Tais interrogações demandam uma responsabilidade política - no sentido mais imediato da palavra responsabilidade; como "responder por" - na medida em que esse "todos" é sempre um recorte voltado para uma inscrição, para o estabelecimento de um "nós"; de um "todos ... nós"; mas, novamente, "nós quem"? Quem diz "nós"? (Duque-Estrada, 2010, p. 8).

\section{Considerações finais}

Romper com o ideal moderno de subjetividade, significa estabelecer uma relação consigo mesmo, com o conhecimento e com a verdade, que coloca em jogo o próprio ser do "sujeito". Mas, colocar em jogo nosso próprio ser é uma experiência arriscada, que põe em questão tudo aquilo que consideramos fazer parte da nossa "identidade". Pensar nosso ser como "tornar-se", como obra em processo de construção envolve descobrir-se outro, fazer uma experiência radical da alteridade, que não mais se resume a relacionar-se com "outros" diferentes de "mim", diferentes da minha suposta identidade já 
plenamente constituida enquanto tal.

Fugindo da obsessão pedagógica pelo "conteúdo" a ser passado e do estabelecimento do "método" correto para "transmitir conteúdo" de maneira "libertadora", tentamos trazer neste artigo uma outra dimensão da formação humana: o exercício de tornar-se singular e dar-se como exemplo e como modelo provocativo para que os outros invistam também na construção de suas próprias singularidades. É este o projeto "pedagógico" ou "antipedagógico" de Nietzsche:

Desde Sobre o futuro dos nossos estabelecimentos de ensino e, principalmente, Schopenhauer educador, tratava-se mais de mostrar que de dizer: apresentar-se como modelo. O educador é o que afirma egoisticamente a si próprio e, na apresentação inclemente de sua singularidade, se constitui como provocação à manifestação de uma outra singularidade. (MURICY, 2017, p. 30).

\section{Referências}

Bieri, A. (2000). Os estilos em Nietzsche. O que nos faz pensar, n. 14, 121-144

Britto, F. L. (2010). Sobre o conceito de Educação (Bildung) na Filosofia Moderna alemã. Educação on-Line (PUCRJ), 6, 1-14.

Descartes, R. (2001). Meditações Metafísicas. São Paulo: Abril.

Dias, R. (2012). Nietzsche: educador da humanidade. Revista Lampejo, n. 2, 10/2012, 10-16.

Do Valle, L. (2003). Teoria, determinação, complexidade: desafios da reflexão sobre educação. Trabalho, Educação e Saúde, 1(2), 185-201. http://dx.doi. org/10.1590/S1981-77462003000200002

Do Valle, L. (2014). Para além do sujeito isolado. Revista Brasileira de Educação, 19(57), 495-512. http:// dx.doi.org/10.1590/S1413-24782014000200012

Duque-Estrada, P. C. (2010). Jamais se renuncia ao arquivo: notas sobre 'Mal de Arquivo' de Jacques Derrida. Natureza Humana, 12(2), 1-16.

Elias, N. (1994). O processo civilizador. Rio de Janeiro: Jorge Zahar.

Foucault, M. (2006). A Hermenêutica do Sujeito. São Paulo: Martins Fontes.

Marcondes, D. (2007). Iniciação à História da Filosofia. Rio de Janeiro: Jorge Zahar

Muricy, K. (2000). Nietzsche, critico da cultura. Revista Tempo Brasileiro, n. 143, 55-72.
Muricy, K. (2017) Ecce Homo: a autobiografia como gênero filosófico. Rio de Janeiro: Zazie Edições.

Nietzsche, F. (2005) Aurora. São Paulo: Cia das Letras.

Nietzsche, F. (2008) Da Utilidade e do Inconveniente da História para a Vida. São Paulo: Escala.

Nietzsche, F.(2008a). David Strauss: sectário e escritor. São Paulo: Escala

Nietzsche, F. (2003). Schopenhauer educador. In Escritos sobre Educação. (pp. 138-223). São Paulo: Loyola

Sanchez, L. (2008). Desconstruindo as concepções dominantes instituidas sobre o aluno. Travessias, 02(01), 1-12.

Santos, J. L. (2006). O que é cultura?. São Paulo: Brasiliense.

Suarez, R. (2005). Notas sobre o conceito de Bildung (Formação cultural). Kriterion, 46(112), 191-198. http:// dx.doi.org/10.1590/S0100-512X2005000200005

\section{Diogo Bogéa}

Doutor e Mestre em Filosofia (Pontificia Universidade Católica do Rio de Janeiro - PUC-Rio, Rio de Janeiro, RJ, Brasil). Professor de Filosofia e Psicanálise na Faculdade de Educação da Universidade do Estado do Rio de Janeiro (UERJ), Rio de Janeiro, RJ, Brasil.

\section{Endereço para correspondência}

Diogo Bogéa

Rua São Francisco Xavier, 524, sala 12.006, bloco A CEP: 20559-900

Rio de Janeiro, RJ, Brasil. 